\title{
Cianoliquens dos gêneros Coccocarpia, Collema e Leptogium do Parque Estadual da Cantareira, SP, Brasil, depositados no herbário SP
}

\author{
Michel Navarro Benatti ${ }^{1,3}$, Marcos Junji Kitaura ${ }^{1}$, Iane Paula Rego Cunha Dias ${ }^{2}$ e Marcelo Pinto Marcelli ${ }^{1}$
}

Recebido: 24.10.2012; aceito: 31.01.2013

\begin{abstract}
Cyanolichens of genera Coccocarpia, Collema, and Leptogium from Parque Estadual da Cantareira, São Paulo State, Brazil, deposited in the SP herbarium). The survey of the foliose lichen specimens of the Parque Estadual da Cantareira and vicinities, deposited at the SP herbarium, revealed 14 cyanolichen specimens, belonging to seven species of the genera Coccocarpia, Collema, and Leptogium. This is the first record of these species for the area, and includes an identification key, descriptions, comments, and illustrations. Collema fuscovirens is recorded for the first time to South America, Leptogium coralloideum is recorded for the first time to São Paulo State, and a lectotype is selected for L. austroamericanum.
\end{abstract}

Key words: Ascomycota, lichenized fungi, Serra da Mantiqueira

RESUMO - (Cianoliquens dos gêneros Coccocarpia, Collema e Leptogium do Parque Estadual da Cantareira, SP, Brasil, depositadas no herbário SP). O levantamento de espécimes de liquens foliosos do Parque Estadual da Cantareira e arredores depositados no herbário SP inclui 14 espécimes de cianoliquens, pertencentes à sete espécies dos gêneros Coccocarpia, Collema e Leptogium. Este é o primeiro registro dessas espécies para a área, sendo apresentadas uma chave de identificação, descrições, comentários e ilustrações. Collema fuscovirens é citado pela primeira vez para a América do Sul, Leptogium coralloideum pela primeira vez para o Estado de São Paulo e o lectótipo de L. austroamericanum é designado.

Palavras-chave: Ascomycota, fungos liquenizados, Serra da Mantiqueira

\section{Introdução}

O Parque Estadual da Cantareira está situado ao norte do município de São Paulo, entre as latitudes $23^{\circ} 20^{\prime}-23^{\circ} 27^{\prime} \mathrm{S}$ e as longitudes $46^{\circ} 28^{\prime}-46^{\circ} 42^{\prime} \mathrm{W}$, com a média de temperatura anual de $18,2{ }^{\circ} \mathrm{C}$, média de pluviosidade anual de $1.400 \mathrm{~mm}$ e variação de altitude entre 750 e $1.215 \mathrm{~m}$ (Clauset \& Soares 1999).

O Parque conta com área estimada em 7.900 ha distribuídos pelos municípios de São Paulo, Caieiras, Mairiporã e Guarulhos. Está atualmente sob a jurisdição do Instituto Florestal, sob efeito do Artigo $2^{\circ}$ do Código Florestal Brasileiro e, a data efetiva de sua criação é 30 de janeiro de 1963, conforme Decreto Estadual 41.626 (São Paulo 1988).

A área é praticamente coberta por floresta, em sua maior parte de Mata Atlântica (Floresta Ombrófila Densa e Floresta Estacional Semidecídua), bem caracterizada devido à posição geográfica, junto à porção sul da Serra da Mantiqueira (São Paulo 1988). A vegetação é setorizada por fatores geomorfológicos somados aos fatores de interferência humana, tais como: abertura de pequenas clareiras, áreas de reflorestamento experimental do Instituto Florestal e antigos sítios remanescentes (São Paulo 1988).

O número de espécies de fungos liquenizados para a Mata Atlântica do Brasil é de aproximadamente 400 , porém foram estimadas 850 para a região na qual a Serra da Cantareira está inclusa (Marcelli 1998). Entretanto, até o presente, cerca de 111 espécies de fungos liquenizados são conhecidas para a região da Serra da Cantareira, pertencentes a 47 gêneros (Marcelli 1998), sem maiores detalhes sobre as espécies.

Este trabalho é parte do levantamento das espécies de liquens foliosos que ocorre no Parque Estadual da Cantareira e regiões circunvizinhas e tem o objetivo de descrever o material de cianoliquens que está

1. Instituto de Botânica, Núcleo de Pesquisa em Micologia, Caixa Postal 68041, 04045-972 São Paulo, SP, Brasil

2. UNISULMA, Coordenação de Ciências Biológicas, Rua São Pedro 11, Jardim Cristo Rei, 65907-070 Imperatriz, MA, Brasil

3. Autor para correspondência: michel_benatti@yahoo.com.br 
depositado no herbário SP, fornecendo uma chave artificial de identificação, descrições, comentários e dados sobre as localidades das espécies.

\section{Material e métodos}

O material estudado faz parte da coleção de liquens do herbário Maria Eneyda P. Kauffmann Fidalgo (SP) do Instituto de Botânica e foi coletado na área do Parque Estadual da Cantareira.

As espécies de Coccocarpia Pers. e Collema Weber ex F. H. Wigg. foram descritas através de protocolos adaptados e as espécies de Leptogium (Ach.) S.F. Gray pelo protocolo criado por Cunha (2007), mas modificado por Kitaura (2012). A morfologia dos talos e apotécios foi descrita de acordo com Kitaura (2012) e Kitaura \& Marcelli (2012), enquanto os tipos de tecidos plectenquimáticos foram padronizados de acordo Degelius (1954) e Kitaura (2012).

A corona foi descrita apenas para as espécies de Leptogium e se formam quando há o acúmulo de cianobactérias na região apical dos anfitécios amarelados (Marcelli et al. 2007). Cunha (2007) observou que a corona de algumas espécies podem originar ornamentos e destacou esta característica como taxonomicamente importante para o gênero.

A metodologia para coleta de fungos liquenizados foliosos é padronizada e pode ser encontrada descrita em Hale (1987), Malcolm \& Galloway (1997) e Benatti \& Marcelli (2007). As análises morfológicas consistiram na observação das características macro e microscópicas dos espécimes, através de microscópio estereoscópico e microscópio óptico comum. Foram analisadas as estruturas somáticas e de reprodução, tanto direta como indireta dos talos.

O material coletado na área do Parque Estadual da Cantareira e depositado no herbário SP do Instituto de Botânica foi identificado conforme metodologia tradicional em liquenologia, descrita em Fink (1905), Hale (1979) e Galloway $(1985,2007)$ para as espécies de Coccocarpia, e conforme Degelius (1954) e Kitaura \& Marcelli (2012) para as espécies de Collema e Leptogium, respectivamente. A maioria das espécies de Leptogium apresenta ascósporos submuriforme ou muriforme e podem ser descritos pelo número de células que apresentam.

\section{Resultados e Discussão}

Foram encontradas e analisadas 14 amostras de fungos liquenizados foliosos com cianobactérias como fotobiontes do Parque Estadual da Cantareira e regiões circunvizinhas, depositadas no herbário SP, e que compreendem sete espécies pertencentes aos gêneros Coccocarpia (2), da família Coccocarpiaceae Henssen; Collema (1) e Leptogium (4), da família Collemataceae Zenker.

Com exceção de Collema fuscovirens (With.) J.R. Laundon, as demais espécies são conhecidas para o Brasil. Embora existam poucas citações (vide distribuição geográfica das espécies), este é o primeiro registro para a localidade de estudo, para uma densa área florestal em meio a maior região urbana do continente sul americano e a primeira citação para uma reserva de Mata Atlântica em meio urbano no Brasil.

Neste trabalho, Leptogium coralloideum (Meyen $\&$ Flotow) Vainio é descrito pela primeira vez para o Estado de São Paulo. A espécie é conhecida para os Estados de Minas Gerais, Mato Grosso do Sul, Paraná, Rio de Janeiro e Rio Grande do Sul, mas ainda não tinha sido citada para São Paulo.

Coccocarpia palmicola (Spreng.) Arv. \& D.J. Galloway, Collema fuscovirens, Leptogium austroamericanum (Malme) C.W. Dodge e L. coralloideum são espécies isidiadas, enquanto que Coccocarpia pellita (Ach.) Müll. Arg. apresenta lóbulos e Leptogium denticulatum Nyl., dentículos. Leptogium moluccanum (Pers.) Vain. não apresenta propágulos ou ornamentos, mas forma apotécios.

A maior parte dos espécimes é corticícola e foi encontrada sobre troncos, galhos ou ramos de árvores. Entretanto, espécimes de Coccocarpia pellita (M.P. Marcelli 16936) foram encontrados crescendo entrelaçados com briófitas (musgos e hepáticas); o espécime de Collema fuscovirens sobre terra e os espécimes de Leptogium coralloideum (M.P. Marcelli 9789 e 9790) sobre rocha.

Poucos espécimes apresentaram apotécios desenvolvidos com ascósporos maduros, como os espécimes de Coccocarpia pellita, Leptogium denticulatum e L. moluccanum. Apesar da aparência gelatinosa quando úmidos, os apotécios das espécies de Leptogium apresentam um complexo arranjo de tecidos que podem ser distinguidos. Em C. pellita e L. denticulatum foram encontrados picnídios.

Ao analisar as secções transversais dos talos de Coccocarpia, diferenças anatômicas nas hifas do córtex inferior não foram encontradas e, ao contrário de Arvidsson (1982), não consideramos os talos das espécies analisadas heterômeros. O córtex inferior de 
Coccocarpia palmicola é composto por uma única camada de hifas com paredes hialinas, enquanto que o córtex inferior de C. pellita tem camadas com diferentes cores de paredes, internas hialinas e mais externas enegrecidas. Apesar das camadas apresentarem cores diferentes, as hifas formam um único tecido e não podem ser separadas.
Uma vez que as espécies de cianoliquens dos gêneros Collema e Leptogium não apresentam concentrações de metabólitos secundários, não se faz necessária análise química em espécies destes gêneros, como ocorre em espécies de Parmeliaceae e Physciaceae. Substâncias liquênicas são raras em espécies do gênero Coccocarpia (Arvidsson 1982).

Chave artificial de identificação das espécies de cianoliquens do Parque Estadual da Cantareira depositadas no herbário SP

1. Talo cinza prateado ou cinza chumbo e superfície com anéis concêntricos

2. Isídios granulares a cilíndricos ou bulados, lóbulos ou lacínulas ausentes, superfície inferior marrom clara a ocre Coccocarpia palmicola

2. Isídios ausentes, lóbulos espalhados sobre a lâmina, superfície inferior negra Coccocarpia pellita

1. Talo cinza, azulado, enegrecido ou esverdeado e superfície sem anéis concêntricos

3. Talo sem isídios e com apotécios

4. Apotécios com a margem do anfitécio lisa Leptogium moluccanum 4. Apotécios com a margem do anfitécio denticulada Leptogium denticulatum

3. Talo com isídios e sem apotécios

5. Córtex sem uma camada celular definida, composto apenas de hifas aglutinadas e perpendiculares Collema fuscovirens

5. Córtex composto por uma camada simples de células paraplectenquimáticas

6. Superfície com rúgulas e isídios com sulcos longitudinais Leptogium austroamericanum 6. Superfície pregueada e isídios cilíndricos e achatados Leptogium coralloideum

Coccocarpia palmicola (Spreng.) Arv. \& D.J. Galloway, Botaniska Notiser 132: 242. $1979 \equiv$ Lecidea palmicola Spreng. Kungliga Svenska Vetenskapsakademiens Nya Handligar 1: 46. 1820. Tipo: GUADALUPE, 1817, coletor deconhecido, s.n. (TO, lectotipo n.v.).

Figuras 1-2

Talo corticícola, cinza-prateado, cinza-escuro quando umedecido, fragmentado, fragmentos 1,0-3,5 cm diâm. Lobos 0,5-3,5(-5,0) mm larg., planos a levemente convexos, contíguos ou lateralmente sobrepostos; ápices arredondados, planos a levemente involutos, lisos; margens laterais planas ou levemente involutas, lisas, sinuosas. Superfície superior lisa com anéis concêntricos a olho nu, estrias longitudinais quando observada em diferentes aumentos. Isídios granulares a cilíndricos ou bulados, eretos a procumbentes, firmes, laminais, abundantes, simples a ramificados, não coralóides, 0,2-1,0 × 0,05-0,10 mm, concoloridos com o talo ou escurecidos, alguns isídios desenvolvem estruturas auriculares. Lóbulos ou lacínulas ausentes. Superfície inferior marromclara a ocre, lisa a rugulosa com estrias longitudinais suaves, geralmente a margem não apresenta rizinas. Rizinas negras a verde-azuladas enegrecidas,
0,4-3,0 mm compr., densas, homogêneas. Secção transversal do talo 100-150 $\mu \mathrm{m}$ de espessura, córtex superior coloplectenquimático 12-20 $\mu \mathrm{m}$ (4-7 células) de espessura; camada de fotobionte com arranjo perpendicular a irregular das cianobactérias, com hifas que ligam o córtex superior com o inferior (hifas colunares paraplectenquimáticas); camada medular ausente, hifas não diferenciadas do córtex inferior; córtex inferior coloplectenquimático 25-35 $\mu \mathrm{m}$ (5-8 células) de espessura, sem carbonização. Rizinas de hifas aglutinadas constituídas por células alongadas, paredes hialinas na base e enegrecidas no ápice. Apotécios e picnídios não encontrados.

Distribuição conhecida: Polinésia, Oceania, Ásia, África, América do Norte, América Central, Caribe e América do Sul. No Brasil é citada para os Estados de AM, BA, MA, MG, MT, PA, PE, RJ, RS, SC e SP (Arvidsson 1982, Swinscow \& Krog 1988, Marcelli 1990, 1991, Spielmann 2006, Lücking et al. 2007, Coca \& Sanin 2010, Gumboski \& Eliasaro 2011).

Material estudado: BRASIL. SÃo PAULO: São Paulo, Parque Estadual da Cantareira, V-2000, leg. M.N. Benatti 341 (SP); idem, VI-2000, leg. M.N. Benatti 1008 (SP); idem, Bairro da Cachoeira, sopé da Serra 

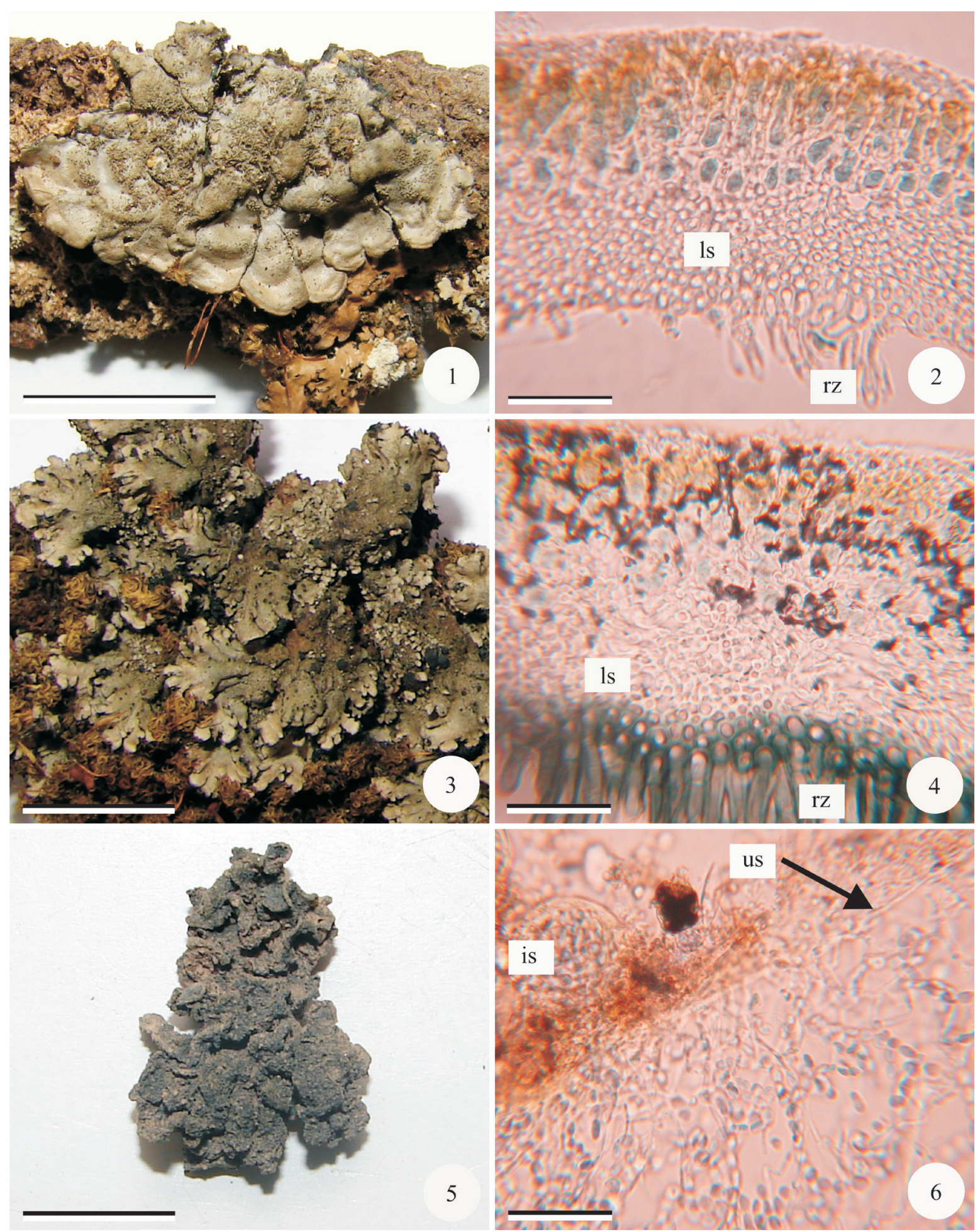

Figuras 1-6. 1-2. Coccocarpia palmicola (M.N. Benatti 341). 1. Detalhe da superfície superior. 2. Secção transversal do talo. 3-4. Coccocarpia pellita (M.P. Marcelli 16936). 3. Detalhe da superfície superior . 4. Secção transversal do talo. 5-6. Collema fuscovirens (M.P. Marcelli 19821). 5. Detalhe da superfície. 6. Secção transversal do talo. Barra 1,3,5=1 cm; 2,4,6=300 $\mu$ m. us: córtex superior; 1s: córtex inferior; rz: rizina; is: isídio.

Figures 1-6. 1-2. Coccocarpia palmicola (M.N. Benatti 341). 1. Detail of the upper surface. 2. Transversal section of the thallus. 3-4. Coccocarpia pellita (M.P. Marcelli 16936). 3. Detail of the upper surface. 4. Transversal section of the thallus. 5-6. Collema fuscovirens (M.P. Marcelli 19821). 5. Detail of the upper surface. 6. Transversal section of the thallus. Bars $1,3,5=1 \mathrm{~cm} ; 2,4,6=300 \mu \mathrm{m}$. us: upper cortex; ls: lower cortex; rz: rhizine; is: isidium. 
da Cantareira, próximo à Rodovia Fernão Dias, 20-VII-1990, leg. M.P. Marcelli, A. Rezende, O. Yano \& R.C. Lourenço 9795 (SP).

Comentários: Coccocarpia palmicola pode ser identificada pela coloração cinza-prata, lobos arredondados com distintas estrias longitudinais e linhas concêntricas, densa produção de isídios simples a ramificados que cobrem largamente o córtex superior e a coloração verde-azulada das rizinas, que se originam no córtex inferior marrom-claro. Pode ser diferenciada de $C$. pellita que produz principalmente lóbulos (inicialmente com aspecto isidióide), e que tem rizinas negras no córtex inferior também enegrecido.

Coccocarpia pellita (Ach.) Müll. Arg., Flora Allg. Bot. Ztg. (Jena) 65: 320. 1882 三 Parmelia pellita Acharius. Lichenografia Universalis: 468. 1810. Tipo: ÍNDIASOCIDENTAIS, O.Swartzs.n.(H-ACH1299, lectotipo n.v.; H-NYL 30996, S, duplicata, n.v., fide Arvidsson 1982).

Figuras 3-4

Talo corticícola (muscícola), cinza-chumbo, cinzaescuro quando umedecido, fragmentado, fragmentos 1,5-3,5 cm diâm. Lobos 0,5-2,0(-5,0) mm larg., planos a levemente convexos, contíguos ou lateralmente sobrepostos; ápices arredondados a levemente truncados, lisos ou lobulados; margens laterais planas ou pouco involutas, lisas, sinuosas. Superfície superior lisa e com anéis concêntricos a olho nu, ocasionalmente com linhas muito sutis, estrias longitudinais quando observada em diferentes aumentos. Isídios ausentes. Lóbulos abundantes, inicialmente granulares e eretos, tornando-se lobuliformes e achatados, laminais a parcialmente marginais, arredondados a irregulares, simples a raramente ramificados, firmes, $0,2-0,6(-1,0) \times 0,1-0,3(-0,5) \mathrm{mm}$, superfície inferior negra, camadas externas carbonizadas. Rizinas negras, 0,5-3,5 mm compr., homogêneas. Apotécios 0,2-2,0(-3,5) mm diâm., planos a convexos, circulares a irregulares, laminais, sésseis a adnatos, margem talina ausente, disco enegrecido, imperfurado, não pruinoso. Seção transversal do talo 100-125 $\mu \mathrm{m}$ de espessura, córtex superior coloplectenquimático 7,5-12 $\mu \mathrm{m}$ (3-5 células) de espessura; camada de fotobionte com arranjo irregular ou perpendicular das cianobactérias, hifas desorganizadas que ligam o córtex superior com o inferior (hifas colunares); camada medular ausente, córtex inferior constituído por células alongadas ou coloplectenquimáticas $60-70 \mu \mathrm{m}$ (até 8 células) de espessura, camadas de células mais externas com as paredes enegrecidas, porém com o mesmo formato que as camadas mais internas. Rizinas de hifas aglutinadas constituídas de células alongadas, paredes enegrecidas da base ao ápice. Apotécio com himênio 50-63 $\mu \mathrm{m}$ alt., sub-himênio coloplectenquimático 35-40 $\mu \mathrm{m}$ (ca. 10 células) de espessura; hipotécio indistinto; excípulo próprio coloplectenquimático levemente carbonizado. Ascósporos elipsóides a fusiformes, simples, incolores, 8 por asco, $(8,0-) 10,0-14,0(-15,0) \times(3,0-) 4,0-5,0 \mu \mathrm{m}$, comumente com gotas de óleo, epispório fino, sutil. Picnídios laminais no talo e nos lóbulos, ostíolo negro; conídios baciliformes $2,5 \times 1,25 \mu \mathrm{m}$.

Distribuição conhecida: Oceania, Ásia, África, América Central, Caribe e América do Sul. No Brasil é citada para os Estados de AM, MG, MT, PA, RJ, RS, SC e SP (Arvidsson 1982, Swinscow \& Krog 1988, Marcelli 1990, 1991, Spielmann 2006, Lücking et al. 2007, Coca \& Sanin 2010, Gumboski \& Eliasaro 2011).

Material estudado: BRASIL. SÃo PAULO: Mairiporã, Serra da Cantareira, próximo a um pomar com clareiras rochosas, II-1981, leg. M.P. Marcelli 16936 (SP).

Comentários: O único espécime encontrado foi colocado em Coccocarpia pellita devido a morfologia apresentada. Na bibliografia, esta espécie apresenta uma ampla variação de características (Arvidsson 1982, Swinscow \& Krog 1988, Lücking et al. 2007) e necessita de revisão pormenorizada do material tipo para averiguação quanto a possibilidade de estar englobando múltiplos táxons similares sob este nome.

O talo possui estruturas que inicialmente assemelham-se a pequenos isídios cilíndricos, mas logo tornam-se lóbulos achatados com a mesma organização anatômica do talo. Os apotécios vistos são numerosos e todos enegrecidos, mas com himênio e ascósporos facilmente visualizáveis.

Os lóbulos, os apotécios e o tamanho e a forma dos ascósporos tornam o material semelhante a Coccocarpia erythroxyli (Spreng.) Swinscow \& Krog, outra espécie problemática que necessita de revisão. Entretanto, Coccocarpia erythroxyli apresenta lobos de 2-12 mm larg. e lóbulos arredondados, laminais, escassos e adventícios, sem a aparência isidióide nos estágios iniciais (Arvidsson 1982, Lücking et al. 2007), enquanto $C$. pellita tem lobos 0,5-2,0(-5,0) mm larg. e lóbulos arredondados a irregulares, principalmente laminais e abundantes, que apresentam aparência isidióide quando jovem. 
Collema fuscovirens (With.) J.R. Laudon. Lichenologist 16:219. 1984 ELichen fuscovirens With. A botanical arrangement of all the vegetables naturally growing in Great Britain 1-2: 717. 1776. Tipo: Ilustração em Dillenius Historia Muscorum, 1742, 138, tab. 19, fig. 22 (holótipo).

= Collema tuneforme (Ach.) Ach. Lichenogr. Univer. : 649. 1810. Tipo: Suécia, "Habitat ad latera praerupta montium calcareorum. Kalmarden Ostro-Gothiae", 1.c. - 1795, leg. Swartz, s.n. (lectotype, Herb. Ach., fide Degelius 1954).

Figuras 5-6

Talo negro quando seco, opaco, fosco, esverdeado quando observado à lupa. Lobos até $5 \mathrm{~mm}$ larg., amontoados, presos em pontos, ascendentes, superfície superior irregularmente rugosa quando observada em diferentes aumentos; ápices redondos, involutos a ascendentes, lisos a irregulares; margens laterais irregulares ou ornamentadas, ascendentes, onduladas; lado de baixo esverdeado, rugoso quando observado em diferentes aumentos. Isídios granulares a curto cilíndricos, lisos, 0,05-0,20 × 0,05-0,15 mm, simples a coralóides, eretos, firmes, concoloridos a negros, laminais e raros marginais, agrupados, abundantes. Lóbulos arredondados a irregulares, ápice arredondado, 0,30-0,45 × 0,45-0,55 mm, simples, eretos, firmes, concoloridos a negros, laminais, casuais, raros a frequentes. Fixação por hápteros; rizinas ausentes; hápteros não marcam a superfície superior, homogêneos, poucos; pêlos ausentes. Apotécios ausentes. Secção transversal do talo até $550 \mu \mathrm{m}$ de espessura, células quadráticas dos córtices ausentes, hifas aglutinadas perpendiculares dos córtices formando uma camada delgada 2,5-5,0 $\mu \mathrm{m}$ de espessura; hifas colunares ausentes. Cianobactérias verdes, abundantes, até 25 células esféricas no filamento, 2,5 × 2,5 $\mu \mathrm{m}$. Gelatina abundante, hialina. Picnídios ausentes.

Distribuição conhecida: Ásia, Europa, África e América do Norte (Schultz et al. 2004). Esta é a primeira citação para a América do Sul.

Material estudado: BRASIL. São PAULo: São Paulo, Bairro da Cachoeira, sopé da Serra da Cantareira, próximo à Rodovia Fernão Dias, 20-VII-1990, leg. M.P. Marcelli, A. Rezende, O. Yano \& R.C. Lourenço 9821 (SP).

Comentários: Collema fuscovirens é espécie saxícola que foi coletada sobre solo. O talo está bastante fragmentado e a exsicata está sem o substrato. A espécie apresenta talos com 3 a $5 \mathrm{~cm}$ de diâmetro (Schultz et al. 2004) e normalmente é coletada com a rocha, o que garante a preservação do talo.

Collema flaccidum (Ach.) Ach. difere de Collema fuscovirens pelo tipo de isídio. C. flaccidum apresenta isídios granulares a achatados (Schultz et al. 2004), enquanto $C$. fuscovirens apresenta isídios granulares a cilíndricos curtos. C. subflaccidum Degel. apresenta superfície lisa e é uma espécie corticícola, diferindo de C. fuscovirens que apresenta superfície irregularmente rugosa e é espécie normalmente saxícola.

A espessura do talo de Collema fuscovirens mencionada para o deserto de Sonora é de (70-)110-200(-300) $\mu \mathrm{m}$ (Schultz et al. 2004) e provavelmente o espécime coletado no Parque Estadual da Cantareira pode ser nova para a ciência. Porém, preferimos manter em Collema fuscovirens até que o material tipo seja examinado.

Leptogium austroamericanum (Malme) C.W. Dodge, Annals of the Missouri Botanical Garden 20: 419. $1933 \equiv$ Leptogium cyanescens (Rabenhorst) Körber var. austroamericanum Malme, Arkiv for Botanik 19: 21.1924. Tipo:BRASIL, RioGrandedo Sul: Colônia Santo Ângelo pr. Cachoeira [atual Município de Agudo], G.O.Malme950B,03-IX-1893(S!,lectótipo aqui designado; G.O. Malme 950 A! e D!, duplicatas).

Figura 7

Talo cinza, opaco, fosco, cinza-claro a azulado quando observado à lupa. Lobos até $5 \mathrm{~mm}$ larg., sobrepostos a amontoados, adpressos ou presos em pontos, adnatos ou ascendentes; superfície superior lisa quando observada a olho nu e com rúgulas longitudinais a irregulares quando observada em diferentes aumentos; ápices redondos, revolutos a ascendentes, lisos ou ornamentados; margens laterais geralmente ornamentadas, planas a ascendentes, onduladas; lado de baixo cinza-claro a esbranquiçado, liso quando observado a olho nu e ruguloso quando observado em diferentes aumentos. Isídios cilíndricos, com sulcos longitudinais, $0,10-0,20 \times 0,50 \mathrm{~mm}$, simples, eretos, firmes, concoloridos com o talo, laminais e marginais, agrupados, frequentes, inicialmente granulares transformando-se em cilíndricos com sulcos longitudinais (aparência de murchos). Lóbulos arredondados, ápices arredondados, 0,25-0,50 × 0,25-0,50 mm, simples, eretos, firmes, concoloridos com o talo, laminais e marginais, casuais a agrupados, frequentes. Fixação por hápteros; 


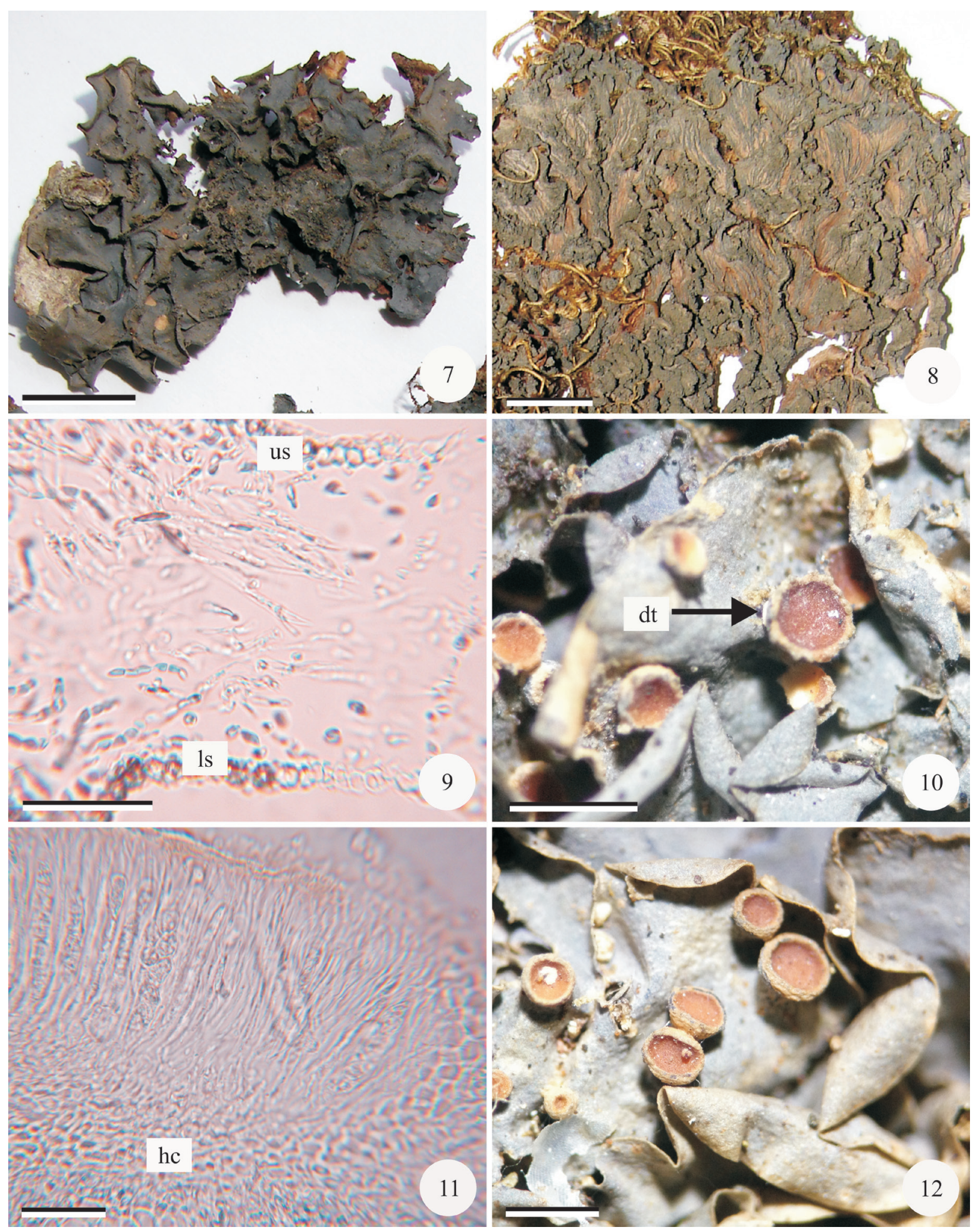

Figuras 7-12. 7. Leptogium austroamericanum (M.P. Marcelli 11496). 8-9. Leptogium coralloideum (M.P. Marcelli 16933). 8. Superfície superior. 9. Secção transversal do talo. 10-11. Leptogium denticulatum (M.P. Marcelli 9758). 10. Detalhe do apotécio. 11. Secção transversal do apotécio. 12. Apotécios de Leptogium moluccanum (M.P. Marcelli 16918). Barra 7,8=1 cm; 9,11=300 $\mu \mathrm{m} ; 10,12=3 \mathrm{~mm}$. 1s: córtex inferior; us: córtex superior; hc: hipotécio coloplectenquimático; dt: dentículos.

Figures 7-12. 7. Detail of the upper surface of Leptogium austroamericanum (M.P. Marcelli 11496). 8-9. Leptogium coralloideum (M.P. Marcelli 16933). 8. Upper surface. 9 Transversal section of the thallus. 10-11. Leptogium denticulatum (M.P. Marcelli 9758). 10. Detail of the apothecia. 11. Transversal section of the apothecia. 12. Apothecia of Leptogium moluccanum (M.P. Marcelli 16918). Bars 7,8=1 cm; $9,11=300 \mu \mathrm{m} ; 10,12=3 \mathrm{~mm}$. 1s: lower cortex; us: upper cortex; hc: colloplectenchymatous hypothecia; dt: denticules. 
rizinas ausentes; hápteros marcam a superfície superior, homogêneos, frequentes; pêlos ausentes. Apotécios não encontrados. Secção transversal do talo 67-75 $\mu \mathrm{m}$ de espessura, células quadráticas dos córtices 2,5-5 × 2,5-5 $\mu \mathrm{m}$; hifas colunares $2,5 \mu \mathrm{m}$ de espessura, retas, $3-5$ células, simples. Cianobactérias verdes ou azuis, frequentes, 7-10 células esféricas no filamento, 2,5 $\times 2,5 \mu \mathrm{m}$. Gelatina frequente, hialina. Picnídios ausentes.

Distribuição conhecida: Oceania, Ásia, África, América do Norte, América Central e América do Sul, (Malme 1924, Dodge 1933, Swinscow \& Krog 1988, Galloway 1999, Dube \& Makhija 2010, Feuerer 2012). No Brasil é citada para os Estados de RS e SP (Marcelli 1991, 1998, Feuerer 2012).

Material estudado: BRASIL. São PaUlo: São Paulo, Parque Estadual da Cantareira, próximo ao Lago das Carpas, 25-VI-1991, leg. M.P. Marcelli, A. Rezende, O. Yano \& F.M.M. Coppolla 11495, 11496 (SP); idem, Bairro da Cachoeira, sopé da Serra da Cantareira, próximo à Rodovia Fernão Dias, 20-VII-1990, leg. M.P. Marcelli, A. Rezende, O. Yano \& R.C. Lourenço 9712 (SP).

Comentários: Leptogium austroamericanum é caracterizada pela superfície rugosa quando observada em diferentes aumentos e os isídios têm a aparência murcha. L. austroamericanum difere de Leptogium cyanescens (Rabenh.) Körb. pelo tipo de superfície do talo, sendo lisa em todos os aumentos nesta espécie.

O material tipo citado no protólogo de Leptogium cyanescens var. austroamericanum (Malme 950) apresenta quatro fragmentos e todos estão colados em um único cartão. Kitaura (2012) analisou o material Malme 950 e observou que o tipo é uma mistura de espécies de Leptogium que, de acordo com o Código Internacional de Nomenclatura para Algas, Fungos e Plantas (Melbourne), um lectotipo precisaria ser designado. No presente estudo, os fragmentos foram indicados com as letras A, B, C e D no cartão e aqueles com as letras A, B e D representam a espécie Leptogium austroamericanum, enquanto o fragmento $C$ provavelmente é parte de um espécime de L. coralloideum (Meyen \& Flot.) Vainio. O fragmento $\mathrm{B}$ foi designado aqui como o lectotipo e os fragmentos A e D duplicatas do lectotipo. O fragmento $\mathrm{C}$ foi diferenciado dos demais pelo tipo de superfície do talo e é o único que apresenta pregas. Degelius (dados não publicados) apontou no cartão de Malme 950 que o material indicado aqui como $\mathrm{C}$ era diferente, porém não publicou a proposta de lectotipificação.
Leptogium coralloideum (Meyen \& Flot.) Vain., Annales Academiae Scientiarum Fennicae 6: 110. $1915 \equiv$ Leptogiumdiaphanum var.coralloideum Meyen \& Flot. Nova Acta Academia Caesarea LeopoldinoCarolina Naturae Curiosorum 19, Suppl.: 226. 1843. Tipo: MÉXICO, Orizaba, Fr. Müller (neotipo [designado por Jørgensen (2002)] H-NYL 41268!). Figuras 8-9

Talo até $15 \mathrm{~cm}$ diâm., cinza a negro quando seco, opaco, fosco, podendo ou não apresentar partes amareladas quando observado à lupa. Lobos irregulares até $4 \mathrm{~mm}$ larg., sobrepostos ou amontoados irregularmente, presos em pontos, adnatos a ascendentes; superfície superior pregueada (lisa entre as pregas) a olho nu, com pregas longitudinais a irregulares quando observada em diferentes aumentos; ápices truncados ou irregulares, planos a ascendentes, irregulares; margens laterais lisas e irregulares, planas e ascendentes; lado de baixo cinza-claro a amarelado, pregueado quando observada em diferentes aumentos. Isídios granulares a cilíndricos curtos ou achatados, 0,05-0,1 × 0,05 mm, simples a coralóides, eretos, firmes, concoloridos ou escuros, laminais e marginais, agrupados, frequentes a abundantes, granulares quando jovens e cilíndricos curtos ou achatados quando desenvolvidos. Lóbulos ausentes. Fixação por hápteros; rizinas ausentes; hápteros não marcam a superfície superior, homogêneos, poucos a frequentes; pêlos ausentes. Apotécios ausentes. Secção transversal do talo 88-113 $\mu \mathrm{m}$ de espessura, 162-250 $\mu \mathrm{m}$ de espessura nas pregas, células quadráticas dos córtices com $5 \mu \mathrm{m}$ diâm.; hifas colunares ausentes. Cianobactérias verdes ou azuis, frequentes, 8-15 células esféricas ou elípticas no filamento, $2,5-5 \times 2,5 \mu \mathrm{m}$. Gelatina frequente a abundante, hialina. Picnídios ausentes.

Distribuição conhecida: Oceania, Ásia, África, América do Norte, América Central, e América do Sul (Vainio 1915, Dodge 1933, Galloway \& Jørgensen 1995, Jørgensen \& Nash III 2004, Dube \& Makhija 2010). No Brasil, a espécie ocorre nos Estados de MG, MS, PR, RJ e RS (Meyen \& Flotow 1843, Malme 1924, Aptroot 2002, Spielmann 2006, Feuerer 2012) e está sendo citada pela primeira vez para o Estado de SP.

Material estudado: BRASIL. São PAULO: São Paulo, Bairro da Cachoeira, sopé da Serra da Cantareira, próximo a uma fonte, 20-VII-1990, leg. M. P. Marcelli, 
A. Rezende, O. Yano \& R. C. Lourenço 9789, 9790 (SP). Idem, Mairiporã, Serra da Cantareira, em mata de encosta perto de pomar com clareiras rochosas, II1981, leg. M. P. Marcelli 16914, 16933 (SP).

Comentários: Leptogium coralloideum é caracterizada pela presença de superfície pregueada com isídios cilíndricos curtos ou achatados sobre as pregas. Essa espécie é considerada a contraparte isidiada de L. phyllocarpum (Pers.) Mont. (Jørgensen \& Nash III 2004) e dificilmente é encontrada com apotécios.

A superfície de Leptogium milligranum Sierk é semelhante à de $L$. coralloideum, porém L. milligranum apresenta apenas isídios granulares simples a coralóides (Kitaura 2012), enquanto que L. coralloideum isídios cilíndricos ou achatados. Leptogium isidiosellum (Riddle) Sierk apresenta isídios cilíndricos que podem ser confundidos com os isídios de L. coralloideum, porém L. isidiosellum apresenta um anfitécio espesso paraplectenquimático (Sierk 1964, Kitaura 2012), enquanto o anfitécio de L. coralloideum é coberto por uma simples camada de tecido paraplectenquimático (Jørgensen \& Nash III 2004).

Leptogium denticulatum Nyl., Annales Sciences Naturelles Botanique et Biologie Vegetale 7: 302. 1867. Tipo: Nova Granada [corresponde atualmente ao território de Panamá, Colômbia, Equador e Venezuela], San Jil [San Gil, Região da Colômbia], 1300 m alt., 1863, Al. Lindg sub-no. 48 (H-NYL 41427!, holótipo).

Figuras 10-11

Talo cinza-claro, opaco, fosco, cinza-claro quando observado à lupa. Lobos até $3 \mathrm{~mm}$ larg., amontoados, presos em pontos, ascendentes; superfície superior lisa quando observada a olho nu, superfície levemente rugulosa e com máculas quando observada em diferentes aumentos; ápices redondos, ascendentes, lisos; margens laterais lisas, ascendentes, onduladas; lado de baixo cinza-claro, liso quando observado a olho nu, levemente ruguloso quando observado em diferentes aumentos. Isídios verdadeiros ausentes, mas com estruturas em forma de dentículos, sem base constrita, plana, ápice agudo, simples, $0,04 \times 0,04 \mathrm{~mm}$, presentes apenas na margem dos apotécios. Lóbulos ausentes. Fixação por hápteros; rizinas ausentes; hápteros não marcam a superfície superior, homogêneos, poucos a frequentes; pêlos ausentes. Apotécios até 0,6 mm diâm., laminais, subpedicelados, planos; margem amarela, denticulada, lisa; anfitécio amarelo, liso, geralmente danificado; corona ausente ou interrompida, evidente, presente nos apotécios jovens e desenvolvidos, origina os dentículos; pedicelo muito curto, $0,05 \mathrm{~mm}$ compr., liso, simples. Secção transversal do talo 33-40 $\mu \mathrm{m}$ de espessura, células quadráticas dos córtices $5 \times 5 \mu \mathrm{m}$; hifas colunares $2,5 \mu \mathrm{m}$ de espessura, retas, 2 células. Cianobactérias azuis, frequentes, número de células não determinado, esféricas, 2,5 $\mu \mathrm{m}$ diâm. Gelatina pouca, hialina. Apotécio com himênio até $95 \mu \mathrm{m}$ de altura; sub-himênio 20-30 $\mu \mathrm{m}$ de altura, translúcido; hipotécio coloplectenquimático 45-55 $\mu \mathrm{m}$ de altura, translúcido; tecido paraplectenquimático sub-himenial ausente, tecido para-himenial até $7 / 8$ da altura do himênio, contínuo ao hipotécio, coloplectenquimático, 15-20 $\mu \mathrm{m}$ (3 células) de espessura no ápice; anfitécio com a mesma altura que o himênio, 20-25 $\mu \mathrm{m}$ (3 células) de espessura no ápice da lateral do córtex, 25-30 $\mu \mathrm{m}$ ( 3 células) de espessura no centro da lateral do córtex, 32-40 $\mu \mathrm{m}$ ( 5 células) de espessura na base do córtex, anfitécio coberto por uma camada de cera semelhante a cutícula das plantas superiores; tecido paraplectenquimático basal ausente. Ascósporos fusiformes, $20-25 \times 7,5-10 \mu \mathrm{m}, 3-4 \times 2$ células, agudos, submuriformes a muriformes. Picnídios laminais a submarginais, ostíolo amarronzado; conídios bifusiformes ou bacilares, 2,5 × 1,2 $\mu \mathrm{m}$.

Comentários: Leptogium denticulatum é caracterizada pela presença de lobos amontoados, superfície lisa a rugulosa, apotécios subpedicelados e dentículos presentes apenas na margem dos apotécios. Essa espécie é semelhante a L. moluccanum (Pers.) Vainio, mas difere pela presença de apotécios denticulados. O hipotécio de $L$. denticulatum é coloplectenquimatoso e difere do hipotécio de L. moluccanum que é prosoplectenquimatoso. Portanto, se os dentículos fossem destruídos, as espécies ainda poderiam ser diferenciadas pelo tipo de tecido do apotécio. Além disso, Leptogium denticulatum não apresenta lóbulos no talo como em $L$. moluccanum var. mastocheilum Vainio (Kitaura 2012).

Distribuição conhecida: Oceania, América do Norte, América Central e América do Sul (Malme 1924, Sierk 1964, Galloway 1999, Jørgensen \& Nash III 2004). No Brasil é citada para os Estados de PR, RS e SP (Cunha 2007, Feuerer 2012).

Material estudado: BRASIL. SÃo PAULo: São Paulo, Bairro da Cachoeira, sopé da Serra da Cantareira, próximo à Rodovia Fernão Dias, 20-VII-1990, leg. M.P. Marcelli, A. Rezende, O. Yano \& R.C. Lourenço 9758 (SP). 
Leptogium moluccanum (Pers.) Vain., Acta Societatis pro fauna et Flora Fennica 75:223. 1890 三 Collema moluccanum Person in C. Gaudichaud, Voyage Uranie:203.1826. Tipo:ILHASMOLUCAS, Rawak, 1817-1820, C. Gaudichaud s/n (PC, holotipo n.v.). Figura 12

Talo cinza-claro, opaco, fosco, cinza-claro quando observado sob a lupa. Lobos até $4,5 \mathrm{~mm}$ larg., amontoados, presos em pontos, adnatos a ascendentes, superfície superior lisa quando observada a olho nu, superfície levemente rugulosa quando observada em diferentes aumentos; ápices redondos, revolutos a ascendentes, lisos; margens laterais lisas, planas a ascendentes, onduladas e sinuosas; lado de baixo cinza-claro, liso quando observado a olho nu, levemente ruguloso quando observado em diferentes aumentos. Isídios ausentes. Lóbulos ausentes. Fixação por hápteros; rizinas ausentes; hápteros marcam a superfície superior, homogêneos, poucos a frequentes; pelos ausentes. Apotécios até $2 \mathrm{~mm}$ diâm., laminais, subpedicelados, discos planos; margem do apotécio amarelada, lisa, simples; anfitécio amarelo, liso; corona interrompida, evidente a distinta, presente nos apotécios jovens e desenvolvidos, não produz outras estruturas; pedicelo muito curto, $0,5 \mathrm{~mm}$ compr., liso, simples. Secção transversal do talo 50-65 $\mu \mathrm{m}$ de espessura, células quadráticas dos córtices $5 \times 5 \mu \mathrm{m}$; hifas colunares $2,5 \mu \mathrm{m}$ de espessura, retas ou inclinadas, 3 células. Cianobactérias azuis, frequentes, número de células no filamento não determinado, esféricas, $5 \mu \mathrm{m}$ diâm. Gelatina pouca, hialina. Apotécio com himênio 115-150 $\mu \mathrm{m}$ alt.; subhimênio 20-25 $\mu \mathrm{m}$ de espessura, translúcido; hipotécio prosoplectenquimático 25-45 $\mu \mathrm{m}$ alt., translúcido; tecido paraplectenquimático sub-himenial ausente; tecido para-himenial com a mesma altura que o himênio, contínuo ao hipotécio, coloplectenquimático, 13-15 $\mu \mathrm{m}$ (2-3 células) de espessura no ápice; anfitécio da mesma altura que o himênio, $17-25 \mu \mathrm{m}$ ( $2-3$ células) de espessura no ápice da lateral do córtex, 12-45 $\mu \mathrm{m}$ (2-3 células) de espessura no centro da lateral do córtex, 37-50 $\mu \mathrm{m}$ (4-6 células) de espessura na base do córtex; tecido paraplectenquimático basal creme, 37-50 $\mu \mathrm{m}$ (4-6 células) de espessura. Ascósporos fusiformes, 17-25 × 7-10 $\mu \mathrm{m}, 3-5 \times 2$ células, ápices agudos, submuriformes a muriformes. Picnídios ausentes.

Distribuição conhecida: Oceania, Ásia, América Central, América do Sul e, para o Brasil, é citada para os Estados de RS e SP (Vainio 1890, Marcelli 1991, Galloway \& Jørgensen 1995, Feuerer 2012).
Material estudado: BRASIL. SÃo PAUlo: Mairiporã, Serra da Cantareira, em mata de encosta perto de pomar com clareiras rochosas, II-1981, leg. M.P. Marcelli 16913, 16918 (SP).

Comentários: Leptogium moluccanum é caracterizada pelos lobos amontoados, apotécios subpedicelados e não ornamentados. O talo de Leptogium moluccanum tem cor acinzentada e apotécios subpedicelados, enquanto o de L. azureum (Sw.) Mont. apresenta cor azulada e seus apotécios são pedicelados.

\section{Agradecimentos}

Os autores agradecem a assessoria pela revisão do artigo. Michel N. Benatti agradece à FAPESP (Fundação de Amparo à Pesquisa do Estado de São Paulo) pela concessão da Bolsa de Iniciação Científica $n^{\circ}$ 00/01009-1. Marcos J. Kitaura agradece a CAPES e à FAPESP pela concessão da bolsa de Doutorado $n^{\circ}$ 2008/51072-3. Marcelo P. Marcelli agradece ao $\mathrm{CNPq}$ (Conselho Nacional de Desenvolvimento Científico e Tecnológico) pela bolsa de produtividade em pesquisa.

\section{Literatura citada}

Aptroot, A. 2002. New and interesting lichens and lichenicolous fungi in Brazil. Fungal Diversity 9: 15-45.

Arvidsson, L. 1982. A monograph of the lichen genus Coccocarpia. Opera Botanica 67: 1-96.

Benatti, M.N. \& Marcelli, M.P. 2007. Gêneros de fungos liquenizados dos manguezais do Sul-Sudeste do Brasil, com enfoque no manguezal do Rio Itanhaém, Estado de São Paulo. Acta Botanica Brasilica 21: 863-878.

Clauset, L.R. \& Soares, D. 1999. Paisagem paulista: áreas protegidas. Empresa das Artes, São Paulo.

Coca, L.F. \& Sanin, D. 2010. Coccocarpia Pers. (Peltigerales-Ascomycetes liquenizados) in Colombia. Tropical Bryology 32: 19-38.

Cunha, I.P.R. 2007. Fungos liquenizados do gênero Leptogium (Ascomycetes) no litoral sul do Estado de São Paulo. Dissertação de Mestrado, Universidade Estadual Paulista, Botucatu.

Degelius, G. 1954. The lichen genus Collema in Europa. Symbolae Botanicae Upsalienses 13: 1-499.

Dodge, C.W. 1933. The foliose and fruticose lichens of Costa Rica I. Annals of the Missouri Botanical Garden 20: 373-467.

Dube, A. \& Makhija, U. 2010. Occurrence of four additional non-hairy species of Leptogium from Maharashtra, India. Lichenologist 42: 701-710. 
Feuerer, T. 2012. Checklists of lichens and lichenicolous fungi. Version 1 January 2012. http://www.checklists. de (acesso em 20.11.1012).

Fink, B. 1905. How to collect and study lichens. The Bryologist 8: 22-27.

Galloway, D.J. 1985. Flora of New Zealand - lichens. Government Printer, Wellington.

Galloway, D.J. 1999. Notes on the lichen genus Leptogium (Collemataceae, Ascomycota) in New Zealand. Nova Hedwigia 64: 317-355.

Galloway, D.J. 2007. Flora of New Zealand Lichens. Revised Second Edition Including Lichen-Forming and Lichenicolous Fungi. Volumes 1 and 2. Manaaki Whenua Press, Lincoln.

Galloway, D.J. \& Jørgensen, P.M. 1995. The lichen genus Leptogium (Collemataceae) in Southern Chile, South America. In: F.J.A. Daniels, M. Schulz \& J. Peine (eds.). Flechten Follmann. Contribution to Lichenology in 243 Honour of Gerhard Follmann, Published by the Geobotanical and Phytotaxonomical Study Group, Botanical Institute, University of Cologne, Germany, pp. 227-247.

Gumboski, E.L. \& Eliasaro, S. 2011. Checklist of lichenized fungi of Santa Catarina State (Brazil). Mycotaxon 115: 535.

Hale, M.E. 1979. How to know the Lichens. The Pictured-Key Nature Series. WM. C. Brown Company Publishers, Dubuque.

Hale, M.E. 1987. How to know the lichens. 2 ed. WCB/ McGraw-Hill, Boston.

Jørgensen, P.M. 2002. (1541-1542) Proposals to reject yhe name Collema proboscidale and to conserve the name Collema phyllocarpum with a conserved type, thereby stabilizing nomenclature of some tropical Leptogium species (Collemataceae, Lecanorales). Taxon 51: 567-568.

Jørgensen, P.M. \& Nash III, T.H. 2004. Leptogium. In: T.H.III Nash III, B.D. Ryan, P. Diederich, C. Gries \& F. Bungartz (eds.). Lichen Flora of the Greater Sonoran Desert Region, v.2. Lichens Unlimited. Arizona State University, Tempe pp. 330-350.

Kitaura, M.J. 2012. Estudos taxonômicos de Leptogium (Ach.) S. F. Gray (Collemataceae, fungos liquenizados). Tese de Doutorado, Universidade Estadual Paulista, Botucatu.

Kitaura, M.J. \& Marcelli, M.P. 2012 . The Leptogium juressianum complex in southeastern Brazil. Mycotaxon 120: 215-221.

Lücking, R., Aptroot, A., Chaves, J.L., Sipman, H.J.M. \& Umaña, L. 2007. A first assessment of the Ticolichen biodiversity inventory in Costa Rica: the genus Coccocarpia (Peltigerales: Coccocarpiaceae). In: I. Kärnefelt \& A. Thell (eds.). Lichenological Contributions in Honour of David Galloway. Bibliotheca Lichenologica 95. J. Cramer in der Gebrüder Borntraeger Verlagsbuchhandlung, Berlin-Stuttgart, pp. 429-457.
Malcolm, W.M. \& Galloway, D.J. 1997. New Zeland Lichens: Checklist, Key and Glossary. Museum of New Zeland Te Papa, Tongarewa.

Malme, G.O.A. 1924. Die Collematazeen dês Regnellschen Herbars. Arkiv för Botanik 19: 1-29.

Marcelli, M.P. 1990. Liquens de restingas e manguezais da ilha do Cardoso. Anais do II Simpósio de Ecossistemas da Costa Sul e Sudeste Brasileira, Águas de Lindóia, SP. v.3: 382-392.

Marcelli, M.P. 1991. Aspects of the foliose lichen flora of the southern-central coast of São Paulo State, Brazil. In: D.J. Galloway (ed.). Tropical Lichens: Their Systematics, Conservation, and Ecology, Systematics Association Special Volume 43. Clarendon Press, Oxford, pp. 151-170.

Marcelli, M.P. 1998. History and current knowledge of Brazilian Lichenology. In: M.P. Marcelli \& M.R.D. Seaward (eds.). Lichenology in Latin America: history, current knowledge and applications. CETESB, São Paulo, pp. 25-45.

Marcelli, M.P., Jungbluth, P., Benatti, M.N., Spielmann, A.A., Canêz, L.S., Cunha, I.P.R. \& Martins, M.F.N. 2007. Some new species and combinations of Brazilian lichenized fungi. Bibliotheca Lichenologica 96: 209-227.

Meyen, J. \& Flotow, J. 1843. Lichenes Exotici Observationes in itinere circum terram institutae (18301832): Lichenes. Nova Acta Academiae Caesareae Leopoldino-Carolinae 19: 209-232.

São Paulo. 1988. Vegetação significativa do Município de São Paulo. Secretaria do Meio Ambiente (SMA), Secretaria Municipal de Planejamento (SEMPLA), São Paulo.

Schultz, M., Ryan, B.D. \& Nash III, T.H. 2004. Collema. In: T.H. Nash III, B.D. Ryan, P. Diederich, C. Gries \& F. Bungartz (eds.). Lichen Flora of the Greater Sonoran Desert Region. v.2. Lichens Unlimited, Arizona State University, Tempe, Arizona, pp. 65-80.

Sierk, H.A. 1964. The genus Leptogium in North America North of Mexico. The Bryologist 67: 245-317.

Spielmann, A.A. 2006. Checklist of lichens and lichenicolous fungi of Rio Grande do Sul (Brazil). Caderno de Pesquisa. Série Biologia (UNISCS) 18: 7-125.

Swinscow, T.D.V. \& Krog, H. 1988. Macrolichens of East Africa. British Museum of Natural History. London.

Vainio, E.A. 1890. Étude sur la classificationnaturalle et la morphologie des lichens du Brésil. Acta Societatis Pro Fauna et Flora Fennica 7: 1-256.

Vainio, E.A. 1915. Additamentum ad lichenographiam Antillarum illustrandam. Annales Academiae Scientiarum Fennicae 7: 1-226. 
